\title{
Selection Methodology of Potential Sensible Thermal Energy Storage Materials for Medium Temperature Applications
}

\author{
Soukaina Hrifech ${ }^{1,2}$, Hassan Agalit ${ }^{2}$, El Ghali Bennouna ${ }^{2}$ and Abdelaziz Mimet ${ }^{1}$ \\ ${ }^{1}$ Abdelmalek Essaâdi University, Energetic laboratory of mechanical fluids and materials, B.P 2121Tetouan, Morocco \\ ${ }^{2}$ Institut de Recherche en Energie Solaire et Energies Nouvelles-IRESEN, Thermal System Department,16 rue Amir Sidi Mohamed \\ Souissi Rabat, Morocco,
}

\begin{abstract}
Thermal energy storage (TES) component improves the revenue of a concentrating solar power (CSP) plant by allowing more heat to be stored and making the electric energy available during the absence of sunlight. The heat can be stored in three ways (sensible, latent, or thermochemical). The present work aims to identify and select cost-effective sensible TES systems suitable for the medium temperature range (100-300 ${ }^{\circ} \mathrm{C}$ ) applications (e.g. Fresnel CSP plants, industrial waste heat recovery, etc.). Based on a literature review, a selection methodology is developed to select potential candidate solid TES media (e.g. natural rock, concrete, sand, etc. ) as filler material in direct or indirect contact with thermal oil, which is used generally as heat transfer fluid (HTF) for this temperature range. The main criteria and steps of this selection methodology are identified and they take into account the different decisive storage properties as thermo-physical and mechanical properties of the solid media. Finally, the potential candidate TES materials are identified for the targeted application and further indoor experimental investigations are briefly presented.
\end{abstract}

\section{Introduction}

Nowadays, renewables energy are key-players to ensure a cleaner production of needed worldwide electricity, and to reduce the negative impacts of the greenhouse gases emissions (e.g. CO2), generated by the exhaustive exploitation of fossil fuels during the last century, on the globe climate an environment. However, the intermittent nature of these green resources of energy impacts the balance between energy supply and demand. In this scope, concentrating solar power (CSP) technology coupled with a cost-effective (i.e. compared to other expensive storage methods such as electrochemical storage) thermal energy storage (TES) is advantageous, as it enables a dispatchable electricity production. Thermal energy can be stored in three forms (sensible, latent, and thermo-chemical heat) [1]. Both, their degree of maturity and their energy density decrease following their respective decreasing order, and the TES state of the art (i.e. Two-tank molten salts) is based on a sensible storage form. For medium temperature range (100-300 ${ }^{\circ} \mathrm{C}$ ) applications, solar molten salts aren't an option because of their high freezing points (around $220^{\circ} \mathrm{C}$ ), so other storage alternative materials should be considered. To overcome this technological drawback, the present work focuses on the selection of potential and suitable sensible TES media for medium temperature range applications. Firstly, a summary on the added benefits of thermal energy storage to CSP plants is provided. Secondly, a selection methodology is developed based on the different experimental research presented in the literature review, in order to select the most potential solid candidate materials for medium range temperature. Thus, this methodology describes the main criteria and steps to take into account for the selection of these candidates, and it involves the different determined storage proprieties as thermo-physical and mechanical properties of the solid media. At the end, the potential candidate TES materials are selected for the targeted application and further indoor experimental investigations are previewed.

\section{Thermal energy storage}

\subsection{Value of thermal energy storage component to CSP plants}

Thermal energy storage (TES) provides many added values to a CSP plant, and that by allowing exceed solar heat to be stored and restituted for later uses. In that way,

\footnotetext{
"Corresponding author: hrifech@,iresen.org
} 
it solves the major problem of the intermittent nature of solar energy by making it dispatchable, i.e. TES helps to reduce the mismatch between the peaks of energy supply by the sun and those related to the energy demand by delivering the need of electricity in the real time[2]. Moreover, TES helps in protecting the turbine generator steady operation against transient interruption of solar heat supply caused by clouds passages, and that by offering a firm energy to the power bloc [1]. In parallel of the TES technical benefits, it can also enhances the economics of the a CSP plant by shifting the peak solar heat harvesting to periods with high peak electricity price, as well as improving its annual capacity factor by extending the operating period of power block [3]. These technico-economical advantages offered by TES component to a CSP plant were demonstrated by numerical investigation conducted by Madani et al [3]: for example, their simulation results proved that adding a 12 hours TES to a CSP plant, with a solar multiple (SM) of 1,5 increases its annual revenues by an average of 35$44 \%$.[4]

\subsection{Recent development in TES}

Recently, many promising TES techniques have been developed in order to enhance the cost-effectiveness of the storage component. For sensible heat storage, solid media were investigated to be used as filler materiel (e.g. natural rock, ceramics, etc.) in direct or indirect contact with HTF. In direct contact, the solid media are used in packed bed configuration with (air, molten salt, or thermal oil) as HTF. The air has the advantage to be free, non-degradable, non-toxic, and suitable for very high operating temperatures. However, it suffers from a low volumetric heat [5], and a low thermal conductivity. Table 1 presents the physical proprieties of the most utilized HTF [8-9-10]. A pertinent example of indirect contact of solid storage media with HTF was demonstrated by DLR, and it consists of a modular concrete block with an embedded heat tubular heat exchangers.

Latent heat TES has high energy density compared to sensible heat storage, but its major problems are the low thermal conductivity and the poor long stability (with respect to thermal cycle) of the used phase change materials (PCM) [7]. To remedy to these technical challenges, different techniques are under development as: encapsulated PCM, adding heat pipes in order to enhance the heat transfer rates between PCM and the HTF, etc. Moreover, different optimized configurations were considered, such as: shell-and-tube PCM storage with embedded heat pipes; and cascaded latent heat storage system, which is composed of few modules containing different PCMs are connected to each other's in series. Their melting temperatures decrease in the HTF flow direction during the charging process [8].

Table 1. Physical proprieties of usual utilized HTF at average temperature [8-9-10].

\begin{tabular}{|c|c|c|c|c|}
\hline Fluid & $\begin{array}{l}\operatorname{Tmin} / \mathbf{T m} \\
\operatorname{ax}\left({ }^{\circ} \mathrm{C}\right)\end{array}$ & $\begin{array}{c}\rho \\
\left(\mathrm{kg} / \mathrm{m}^{3}\right)\end{array}$ & $\begin{array}{c}\mathrm{Cp} \\
(\mathrm{J} / \mathrm{kg} \\
\mathrm{K})\end{array}$ & $\begin{array}{c}\mathbf{k} \\
(\mathbf{W} / \mathbf{m} \\
\mathbf{K})\end{array}$ \\
\hline Cloria HT43 & $25 / 315$ & 695 & 2700 & 0.16 \\
\hline $\begin{array}{l}\text { Therminol } \\
\text { VP1 }\end{array}$ & $25 / 350$ & 781.5 & 2404 & 0.090 \\
\hline Solar salts & $220 / 600$ & 1835 & 1510 & 0.52 \\
\hline Hitec & $124 / 535$ & 1790 & 1560 & 0.33 \\
\hline Hitec XL & $120 / 500$ & 1990 & 1445 & 0.52 \\
\hline Air & $\geq 1000$ & 0.5 & 1075 & 0.05 \\
\hline
\end{tabular}

\section{Suitable materiel for sensible heat storage}

\subsection{State of the art of sensible heat storage}

The most mature and commercialized sensible TES technology is two-tank molten salts system. In this later, molten salts are used as storage media, and they offer many advantages (e.g. high volumetric heat capacity, and relatively high operating working temperature (up to $\left.600{ }^{\circ} \mathrm{C}\right)$ ) [9]. However, they are relatively expensive, and they have high solidification temperatures (around $220^{\circ} \mathrm{C}$ for solar salt). To reduce the TES component cost, a single tank thermocline system was proposed as a replacement to the stat-of-the art configuration. Thus, both the hot and cold fluid are stored in single tank and separated by the fact of difference between the density that create temperature gradient called thermocline[2]. These unwanted phenomena can be attenuated by the use of filler materials, which act like a porous distributor/matrix inside the tank and maintain its thermal stratification [10], [11]. In addition, when these filler materials are low-cost (e.g. natural rock, or cheap ceramics), the cost of this dual media thermocline TES is much cheaper than that of the two tank molten salt. In fact, this cost reduction was estimated to be around 35\% [12].In the temperature range of the targeted applications, thermal oil is very suitable as HTF in comparison to molten salts. 


\subsection{Natural rocks:}

Natural rocks are an attractive filler materials for duel thermocline TES, as: they are low cost, abundant, and they have good storage properties. However, their suitability and their final selection depend on the assessment of several proprieties, which must be favorable to their stability in general under long term thermal cycling. In this optic, several efforts were conducted to select potential natural rocks candidate[5]. In this context, Becattini et al investigated six Alpine rocks (mafic rocks, felsic rocks, limestone, calcareous sandstone, quartz-rich conglomerates, serpentines) as storage materials for TES in contact with air. These rocks were subject to thermal cycling between 100$600^{\circ} \mathrm{C}$ with a heating rate of $2.6{ }^{\circ} \mathrm{C} / \mathrm{min}$. It was concluded from their study that the specific heat capacities of the studied stones decrease with thermal cycling (20-60 cycles) due to the different thermally induced chemical decompositions (i.e. minerals dehydration, decarbonation of calcite, or/and deserpentinization). Whereas, their respective porosities increase due to the same previous mentioned chemical reactions, as well as to quartz inversion (from $\alpha$ to $\beta$ ) at $573^{\circ} \mathrm{C}$ for the case rocks with high quartz content. As resulted from this experimental study, four suitable rocks were selected, and they are namely: mafic rock, felsic rock, serpentinite, and quartz-rich conglomerate [11]. In the same manner, the influence of minerals composition of rocks on degradation of their physical and mechanical proprieties due to thermal cycling was proved by the investigation of Tiskatine et al.[10] This latter considered thirteen varieties of the following rocks (limestone, marble, granite, rhyolite), which were collected from different region of Morocco and tested under thermal cycling (12-120 cycles) between 20 and $650^{\circ} \mathrm{C}$ with an elevated heating rate $25^{\circ} \mathrm{C} / \mathrm{min}$. The outcomes of this study proved that the main minerals that control the degradation mechanisms (e.g. decrease of the compressive strength) of rocks properties were calcite and quartz; While, the most satisfying rocks with respect to the conducted thermal cycling tests were: Rhyolite and quartzitic-sandstone. Besides the thermophysical proprieties of a natural rock, its structure and texture are also important parameters to take into account as confirmed by Allen et al [5]. In their study, several rocks from South Africa were subject to thermal cycling between 350 and $530^{\circ} \mathrm{C}$ (950 cycles) with a heating rate of $2^{\circ} \mathrm{C} / \mathrm{min}$. At the end of these tests, it was concluded that fined-grained rocks are less cracking compared to the coarse-grained ones; and the foliated rocks were found to be incompatible for TES compared to the non-foliated ones. As result, the selected suitable rocks are: dolerite, some of gneiss, sandstone, and greywacke.

Another important criterion, during the selection of suitable rocks for TES, is their compatibility with the used HTF. In this context, Pacheco et al tested in a first step 17 minerals in direct contact with nitrate salts (Hitec XL) for 10-1000 hours of static exposure [12]. The most successful candidates were: quartzite, taconite, marble, limestone, apatite, corrundum, scheelite, and cassiterite. In a second step, only four rocks of these latter's (namely: quartzite, taconite, marble, and limestone) were thermally cycled (around 350) was tested for between 290 and $400^{\circ} \mathrm{C}$ in direct contact with the same. The obtained results show that the marble and limestone were incompatible with Hitec XL. And finally, both quartzite and taconite were selected as they succeeded the previous test. In the same fashion, Fricker et al. tested several natural rocks specimens under thermal cycling between 20 and $600^{\circ} \mathrm{C}$ in direct contact with air [13]. And only five rocks (granite, peridotite, basalt, gneiss, diabase) were selected, as they withstood the previous thermal cycling test without disintegration or excessive weight loss. As far as it concerns the range of temperature $\left(100-300^{\circ} \mathrm{C}\right)$ targeted in the present paper, H.Grirate et al. tested six rocks (quartzite, basalt, granite, hornfels, cipolin, and marble) in direct static contact with thermal oil at temperatures of $250 / 350{ }^{\circ} \mathrm{C}$ for 500 consecutive hours [14]. As result, quartzite and cipolin rocks were selected as the most suitable filler materials in direct contact with oil for the considered temperature range.

In an effort to identify suitable natural rocks for TES up to $650{ }^{\circ} \mathrm{C}$, a general methodology of selection was proposed by Jemmal et al [15]. It take into account the following important criteria such as: (1) good thermophysical proprieties (e.g. high volumetric heat capacity $\rho \times C_{p}$, high thermal conductivity $k$, low porosity, high compressive strength, and low naturally trapped water in the rock's internal pores), and (2) good long term thermal stability. Using this developed methodology, Moroccan gneiss rocks were selected as suitable rock in direct contact with air for TES at a maximum operating temperature of $550^{\circ} \mathrm{C}[16]$.

\subsection{Ceramics:}

In addition to natural rocks, ceramics are another potential category of filler materials which can be incorporated in the recently proposed TES configurations. S. Khare et al [17], used a commercial materials selector package from Granta CES to identify suitable materiel for high temperature TES (500 -700 $\left.{ }^{\circ} \mathrm{C}\right)$. The main criteria of selection were: the thermophysical properties (density, specific heat capacity, thermal conductivity), and the thermo-mechanical proprieties (thermal expansion, fracture toughness, and bulk modulus). Numerous potential materials candidates were selected to be used in TES application, and they included: ceramics (e.g. alumina and magnesia bricks), and composite materials (e.g. high alumina concretes, silicon carbide, graphite, and ferrous metal). Using the same commercial selector, Fernandez et al proposed (graphite, aluminum alloy, cast irons, and concrete) potential materials in the temperature range of 150 $200^{\circ} \mathrm{C}[18]$.

D. Laing et al [19], studied castable ceramic and high temperature concrete up to $390^{\circ} \mathrm{C}$ in indirect contact synthetic oil as HTF (modular concrete and castable ceramic block with an embedded heat tubular heat 
exchangers); and it was concluded that both materials are suitable for this temperature range. However, high temperature concrete was preferred thanks to its relatively low-cost and high mechanical strength compared to castable ceramics. In the same context, a DLR team of research create a new mixture of concrete, by adding polyethylene fibers, in order to enhance its thermal cycling stability (up to 2250 cycles) for temperatures up to $500^{\circ} \mathrm{C}$ [20].

\section{Methodology of selection}

Based on the previous literature review, a scientific methodology of selection (see Figure 1) was developed in order to identify/develop suitable TES materials for medium range temperature $\left(100-300^{\circ} \mathrm{C}\right)$ applications. Compared to the methodology developed by Jemmal et al [15], the present one is more detailed and it includes the different screening steps for the selection of potential TES candidates material. These steps would be presented and analyzed in the following paragraphs. In the other hand as mentioned in the previous paragraph Khare [17] and Fernandez [18] select their TES materials only based on a selector package which doesn't include the selection of naturel rocks.

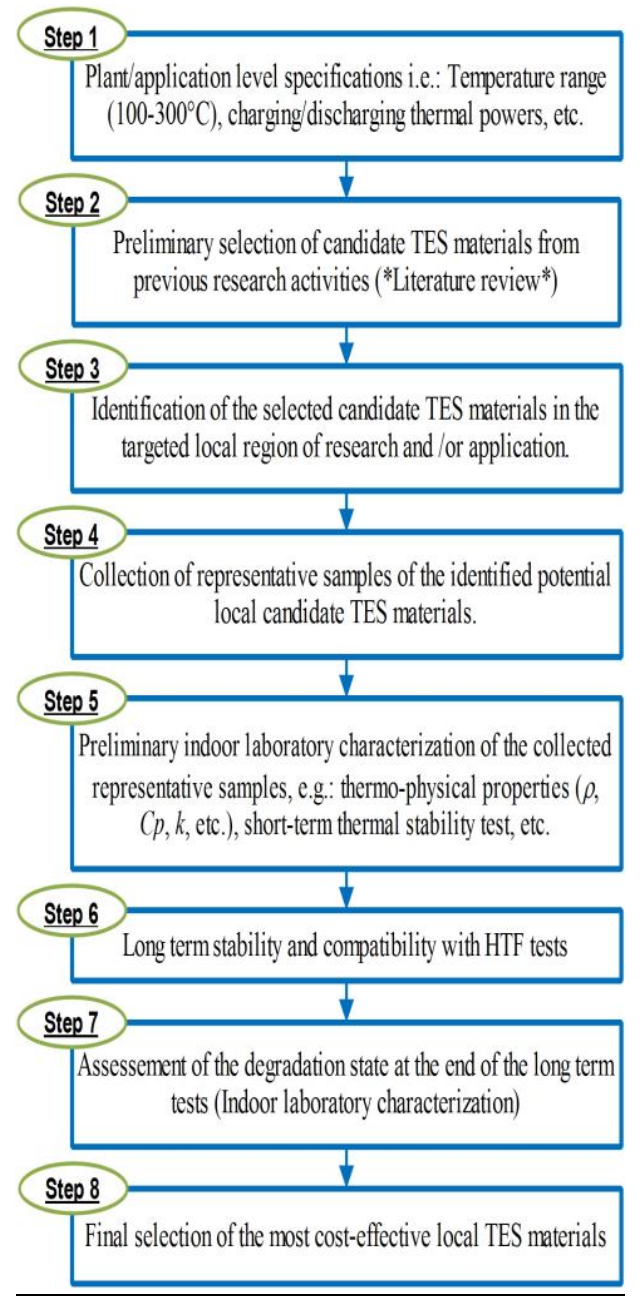

Fig.1.Methodology of selection of potential sensible TES
The first step in the selection of a potential TES materiel is to determine precisely the specifications required by the targeted application (e.g. CSP plant), which include the temperature range $\left(100-300{ }^{\circ} \mathrm{C}\right.$ in our case), charging/discharging thermal powers, storage capacity, etc. In the targeted temperature range, Fresnel reflectors are preferred thanks to their relatively low-cost and thermal oil is usually used as HTF. An illustration of this is the $1 \mathrm{MW}_{\mathrm{e}}$ Fresnel CSP plant installed in the Green Energy Park (Ben Guerir, Morocco). The second step consists of a preliminary selection of potential candidate TES materials, which is based only on a literature review of the previous pertinent research activities in relation with the determined specifications. This literature investigation takes into account the following main criteria: good storage properties, high abundance and availability, and low cost. In the third step, the short list of the selected candidates is identified in the local region/area of research. These latter's may be found in nearby natural quarries in the case of rocks, or produced by local industries in the case of ceramics. Once this step is successfully achieved, a shorter list of available local candidates is determined and their respective representative samples are collected in the fourth step. These samples are subjects to several indoor laboratory characterizations in the fifth step, which aim to verify the following required criteria in the tested TES candidate materials:

-Thermo-physical properties such as: high thermal capacity $\rho \times C_{p}$, thermal conductivity $k$, and low porosity. -Mechanical properties, e.g.: high compressive strength, and young modulus.

-Thermal and mechanical stability, i.e.: absence of physico-chemical degradation of the tested material when they are subjected to a short thermal cycling (up to five cycles).

-Economic and environmental aspects: the collected material cost as well as their associated miscellaneous costs (e.g. manufacturing or transport costs) should be as low as possible. In addition the material should be ecofriendly.

In the sixth step, only the best candidates' materials are selected to pass the long term stability and compatibility tests. These latter's consists of many cycles (up to 2000 cycles) between $100-300^{\circ} \mathrm{C}$ in direct contact with the HTF. Then in the seventh step, a general assessment of the degradation state of the tested samples is performed using different laboratory techniques. The main step is to verify if the positive obtained results during step 5 are conserved after the long-term test. Finally, the most costeffective TES materials are selected in the eighth step to be incorporated in the storage system. 


\section{RESULTS AND DISCUSSION}

In the present paper, the two-first steps of the developed selection methodology (see Figure 1) were performed, and four preliminary potential solid media were selected. They are namely: quartzite rocks, cipolin rocks, concrete, and castable ceramics. This result was discussed in the previous literature review and more details can be found in the cited references. Further work is ongoing to fulfill the remaining steps (3 to 8 ) of selection methodology in order to obtain the best suitable TES material. This later would be tested in a reel prototype scale TES system, which would be installed later in the Green Energy Park (Ben Guerir, Morocco).

\section{Conclusions}

In this paper, a comprehensive literature review of the different recently investigated sensible TES materials was discussed. These materials are destined to medium range temperature $\left(100-300{ }^{\circ} \mathrm{C}\right)$ applications. Based on this bibliographical study, a novel methodology of selection was developed and described. It presents a scientific procedure to select most suitable sensible TES materials for medium rang temperature applications. However, its logic can be used to select TES materials in other temperature ranges applications. Also, it can be applicable to phase change materials (PCMs). Finally, using this methodology four potential candidates sensible TES materials (quartzite rocks, cipolin rocks, concrete, and castable ceramics) were selected for further indoor laboratory investigations.

\section{Reference}

1. S. Kuravi, J. Trahan, D. Y. Goswami, M. M. Rahman, and E. K. Stefanakos, "Thermal energy storage technologies and systems for concentrating solar power plants," Prog. Energy Combust. Sci., vol. 39, no. 4, pp. 285-319, (2013).

2. U. Herrmann and D. W. Kearney, "Survey of Thermal Energy Storage for Parabolic Trough Power Plants," J. Sol. Energy Eng., vol. 124, no. 2, pp. 145-152,( 2002).

3. R. Sioshansi and P. Denholm, "The Value of Concentrating Solar Power and Thermal Energy Storage," IEEE Trans. Sustain. Energy, vol. 1, no. 3, pp. 173-183, (2010).

4. S. H. Madaeni, R. Sioshansi, and P. Denholm, "How Thermal Energy Storage Enhances the Economic Viability of Concentrating Solar Power," Proc. IEEE, vol. 100, no. 2, pp. 335-347, (2012).

5. K. G. Allen, "Performance characteristics of packed bed thermal energy storage for solar thermal power plants," Thesis, Stellenbosch: University of Stellenbosch, (2010).
6. K. G. Allen, T.W.von Backströma, D.G.Krögera, A.F.M.Kistersb "Rock bed storage for solar thermal power plants: Rock characteristics, suitability, and availability -.

7. B. Zalba, J. M. Marín, L. F. Cabeza, and H. Mehling, "Review on thermal energy storage with phase change: materials, heat transfer analysis and applications," Appl. Therm. Eng., vol. 23, no. 3, pp. 251-283, (2003).

8. H. Michels and R. Pitz-Paal, "Cascaded latent heat storage for parabolic trough solar power plants," Sol. Energy, vol. 81, no. 6, pp. 829-837, (2007).

9. D. Kearney et al., "Engineering aspects of a molten salt heat transfer fluid in a trough solar field," Energy, vol. 29, no. 5, pp. 861-870, (2004).

10. R. Tiskatine et al., "Experimental evaluation of thermo-mechanical performances of candidate rocks for use in high temperature thermal storage," Appl. Energy, vol. 171, no. Supplement C, pp. 243-255, (2016).

11. V. Becattini, T. Motmans, A. Zappone, C. Madonna, A. Haselbacher, and A. Steinfeld, "Experimental investigation of the thermal and mechanical stability of rocks for high-temperature thermal-energy storage," Appl. Energy, vol. 203, no. Supplement C, pp. 373-389, (2017).

12. J. E. Pacheco, S. K. Showalter, and W. J. Kolb, "Development of a Molten-Salt Thermocline Thermal Storage System for Parabolic Trough Plants," J. Sol. Energy Eng., vol. 124, no. 2, pp. 153-159, (2002).

13. H.W.Fricker"High-temperature heat storage using natural rock, Solar energy (1991)

14. H.Grirate, H.Agalit, N.Zari, A.Elmachaoui, S. Molina and R.Couturier "Experimental and numerical investigation of potential filler materials for thermal oil thermocline storage. Solar energy (2016)

15. Y. Jemmal, N. Zari, and M. Maaroufi, "Study of rock suitability for high temperature thermal energy storage in concentrated solar tower power plants," in 2015 3rd International Renewable and Sustainable Energy Conference (IRSEC), pp. 1-6,(2015).

16. Y. Jemmal, N. Zari, and M. Maaroufi "Thermophysical and chemical analysis of gneiss rock as low cost candidate material for thermal energy storage in concentrated solar power plants, Solar energy materials and solar cells.(2016)

17. M. Dell'Amico, C. Knight, and S. McGarry, "Selection of materials for high temperature sensible energy storage," Sol. Energy Mater. Sol. Cells, vol. 115, no. Supplement C, pp. 114-122, (2013).

18. A. I. Fernandez, M. Martínez, M. Segarra, I. Martorell, and L. F. Cabeza, "Selection of materials with potential in sensible thermal energy storage," Sol. Energy Mater. Sol. Cells, vol. 94, no. 10, pp. 1723-1729, (2010). 
19. D. Laing, W.-D. Steinmann, R. Tamme, and C. Richter, "Solid media thermal storage for parabolic trough power plants," Sol. Energy, vol. 80, no. 10, pp. 1283-1289, (2006).

20. D. Laing, C. Bahl, T. Bauer, D. Lehmann, and W.D. Steinmann, "Thermal energy storage for direct steam generation," Sol. Energy, vol. 85, no. 4, pp. 627-633, (2011). 